\title{
Uma disputa sobre o sentido da natureza da ciência: uma análise da crítica de Michael Matthews à visão consensual de Norman Lederman
}

\section{A dispute concerning the meaning of the nature of science: an analysis of Michael Matthews' critique of the consensual view by Norman Lederman}

Dodolfo Roda

Roberto de Andrade Martins Universidade Federal de São Paulo (Unifesp), Diadema, SP, Brasil.
Autor correspondente: rodolfo.guidil@unifesp.br

Resumo: Desde o último quarto do século 20 parece haver uma boa aceitação de que o conhecimento sobre a Natureza da Ciência é uma competência crucial para a área de Ensino de Ciências. Uma das justificativas para sua inserção no ensino é a concepção de que uma boa compreensão a respeito da Natureza da Ciência contribui para a alfabetização científica do indivíduo, assim como contribui para a formação do cidadão. Dentre as vertentes e concepções existentes, uma amplamente utilizada no ensino é a visão consensual, personalizada por alguns autores na figura do grupo do professor Norman Lederman. Esta concepção tem sido alvo de muitas críticas ao longo dos anos. O objetivo deste artigo é explorar a crítica realizada pelo professor Michael Matthews, analisando os argumentos utilizados por ele contra a visão consensual de Lederman. Reforçamos ao final do trabalho a importância da contextualização enquanto a crítica é desenvolvida.

Palavras-chave: Natureza da ciência; Visão consensual; Norman Lederman; Educação científica; Caracterização da ciência.

Abstract: Since the last quarter of the $20^{\text {th }}$ century, there has been, apparently, a general acceptance that a good understanding about the Nature of Science is a crucial competence in Science Teaching. One of the reasons for its inclusion in teaching is that a good grasp of the Nature of Science contributes to the individual's scientific literacy and to her/his development as a citizen. Among the several existing strands and conceptions, one that is widely used is the so-called consensus view, pinpointed by some authors in the figure of professor Norman Lederman and his group. This view has been the target of several critiques throughout the years. The goal of this paper is to explore the critique made by professor Michael Matthews, analyzing the arguments raised against Lederman's consensus view. We reinforce at the end of this paper the importance of contextualization in the elaboration of criticism.

Keywords: Nature of science; Consensus View; Norman Lederman; Science education; Features of science.

Recebido em: 09/02/2021

Aprovado em: 04/08/2021 


\section{Introdução}

Desde o último quarto do século 20 parece haver, em todo o mundo, uma grande concordância quanto ao papel desempenhado pela inserção da Natureza da Ciência na educação. Trabalhos como os de Lederman e O'Malley (1990) e Pumfrey (1991) já indicavam essa abordagem como o objetivo mais almejado das propostas inovadoras de currículo e ensino entre os anos 1980 e 1990. Bell e Lederman (2003) nos indicam que a motivação de diversos países que advogaram pela inserção da Natureza da Ciência no ensino, proporcionando dessa forma uma renovação no interesse pela área, reside principalmente na relação dela com o tão almejado letramento científico. Ter uma boa compreensão da Natureza do Conhecimento Científico é uma característica de um indivíduo cientificamente letrado. Para que o indivíduo possa exercer sua cidadania e realizar suas escolhas estando mais bem informado, Praia, Gil-Pérez e Vilches (2007) também afirmam que a Natureza da Ciência desempenha papel fundamental nesse quesito.

Para desenvolver concepções consideradas 'adequadas' a respeito da Natureza da Ciência, faz-se necessário compreender do que se trata essa área do conhecimento, tarefa esta que se mostra complexa desde o início de sua execução. Ora, como aponta Lederman (1986), embora seja mais comum encontrarmos uma definição da Natureza da Ciência referindo-se aos valores e premissas inerentes ao conhecimento científico, encontramos também um grande número de definições e compreensões diferentes a respeito da área. Isso se dá por diferentes questões filosóficas, sociológicas e epistemológicas relacionadas à própria ciência em si.

Todavia, encontramos aqueles que, voltando sua atenção para o âmbito educacional (mais precisamente os anos de formação que compreendemos no contexto brasileiro como educação básica), julgam essas contínuas discussões irrelevantes para os alunos e afirmam que é possível atingir certo grau de generalização e consenso quanto aos aspectos que constituem a Natureza da Ciência, sendo estes relevantes no cotidiano dos estudantes (LEDERMAN; ANTIK; BARTOS, 2014).

Essa visão que se convencionou chamar de 'Visão Consensual' é comumente personificada na figura do professor Norman Lederman e seu grupo de pesquisa, relevantes tanto pelo tempo de atuação quanto pelo grande número de citações de seus trabalhos. Discutiremos a respeito de suas visões mais à frente. É importante, neste momento, apontarmos que, tão numerosas quanto os usos e referências a seu trabalho, parecem ser as críticas feitas a esse (ALLCHIN 2011, 2017; IRZIK; NOLA, 2011; MARTINS, 2015; MATTHEWS, 2012).

O objetivo deste artigo é fazer uma análise da crítica realizada por Matthews (2012), referente aos problemas que ele vê na visão consensual e na elaboração dos itens que compõem a lista presente em Lederman et al. (2002). Iniciaremos pelas críticas feitas, traremos uma breve análise do trabalho do professor Lederman e seu grupo e, por fim, daremos nossas considerações a respeito da pertinência delas em Matthews (2012). 


\section{A crítica de Matthews (2012)}

O professor Michael Matthews, como ele próprio lembra em seu artigo, vem de uma longa tradição de autores que advogam pelos benefícios culturais, educacionais, pessoais e científicos da inserção da História e Filosofia da Ciência em programas educacionais e currículos de ciências ou, em termos atuais, "[...] ensinar a respeito da natureza da ciência (NdC) enquanto se ensina ciências" (MATTHEWS, 2012, p. 3, tradução nossa).

Em um trabalho publicado em 2012, o professor se dedica a apresentar um breve histórico a respeito das discussões envolvendo a Natureza da Ciência, tecendo uma crítica à Visão Consensual, como fora anteriormente mencionado, para, por fim, propor uma "[...] mudança na terminologia e no foco da pesquisa de uma Natureza da Ciência, essencialista e com foco epistemológico, para uma concepção mais relaxada, contextual e heterogênea" (MATTHEWS, 2012, tradução nossa). Ele denominou sua nova proposta como "características da ciência" (features of science). A motivação para essa mudança de terminologia consistiria na possibilidade de evitar aquilo que ele considera "armadilhas filosóficas e educacionais", nas quais muitas pesquisas haviam caído. Estas armadilhas seriam:

1. A confusa mistura de características epistemológicas, sociológicas, psicológicas, éticas, financeiras e filosóficas em uma única lista de aspectos da natureza da ciência.

2. O privilégio dado a uma posição controversa e muito debatida com respeito à metodologia ou 'natureza' da ciência.

3. A pressuposição de uma solução particular à disputa pela demarcação (entre aquilo que se considera ciência e não ciência).

4. A pressuposição de que o aprendizado a respeito da Natureza da Ciência pode ser julgado e avaliado pela capacidade de os alunos identificarem um determinado número de enunciados declarativos a respeito da natureza da ciência. (MATTHEWS, 2012, p. 4, tradução nossa).

Em sua análise da pesquisa contemporânea sobre a Natureza da Ciência, Matthews (2012, p. 9, tradução nossa) reconhece os avanços feitos ao longo dos anos, porém, aponta que muitas dessas pesquisas sofrem devido a "[...] uma abordagem simplória e de uma escrita ambígua em pontos críticos onde assuntos filosóficos estão em jogo". Esses problemas apontados serão encontrados em sua análise do trabalho do grupo do professor Lederman.

Sua primeira crítica explícita se encontra na definição utilizada pelo grupo quando se refere à natureza da ciência. Para Lederman et al. (2002, p. 498, tradução nossa), "[...] tipicamente, Natureza da Ciência se refere à epistemologia e sociologia da ciência, ciência como um meio de conhecer, ou aos valores e crenças inerentes ao conhecimento científico e seu desenvolvimento". O problema, para Matthews, se encontraria na presença de elementos da epistemologia ou metodologia da ciência, que certamente encontrariam limitações, enquanto a sociologia da ciência certamente não os encontraria. Essas limitações encontradas pela epistemologia ou metodologia da ciência, todavia, não ficam claras em seu trabalho, tornando vaga a problemática. 
Suas críticas se voltam, então, para o que ele chama de Os sete de Lederman. Como já havíamos mencionado, o grupo do professor Lederman compreende que há consenso suficiente entre filósofos e historiadores das ciências sobre alguns pontos centrais da Natureza da Ciência. Sendo assim, foi possível selecionar alguns aspectos que, ao atenderem alguns critérios, vieram a constituir uma lista com sete elementos. Seriam estes: a natureza empírica da ciência, teorias e leis científicas, a natureza criativa e imaginativa do conhecimento científico, a influência das teorias no conhecimento científico, a imersão cultural e social do conhecimento científico e, por fim, o mito do método científico. Apresentaremos esses aspectos de maneira mais detalhada na próxima seção.

Para Matthews (2012), há um lado positivo na existência dessa lista, pelo fato de inserir a Natureza da Ciência nas salas de aula. Além disso, estes aspectos fornecem aos pesquisadores um instrumento de medição do aprendizado a respeito da Natureza da Ciência, bem como promove alguma reflexão a respeito desses aspectos. Todavia, ele aponta que a lista é utilizada como se fosse "um mantra ou um catecismo" (MATTHEWS, 2012, p. 11, tradução nossa). De fato, tal uso acrítico vai contra o próprio objetivo de inserção da Natureza da Ciência no ensino.

Por fim, para Matthews (2012), esses sete elementos da Natureza da Ciência, destacados em Lederman et al. (2002), carecem de um maior refinamento histórico e filosófico, devendo ser desenvolvidos para sua utilização em sala de aula. Ele procura mostrar que existe uma ambiguidade filosófica em todos os itens da lista, reforçando seu argumento de que estes deveriam ser mais bem desenvolvidos.

Como solução para esse problema, Matthews propõe a mudança de terminologia de 'Natureza da Ciência' para 'Características da Ciência', sugerindo como exemplo outros 11 aspectos que ele considera relevantes. Seriam estes: experimentação, idealização, modelos, valores e questões sociocientíficas, matematização, tecnologia, explicação, visões de mundo e religião, escolha de teoria e racionalidade, feminismo, realismo e construtivismo. Os temas deveriam ser trabalhados juntamente com episódios históricos, dos quais estes surgiriam com maior naturalidade.

\section{Sobre Lederman e a visão consensual}

Antes de nos aventurarmos em discutir a respeito da visão consensual, personificada por Matthews na figura do grupo de Lederman, é necessário introduzirmos uma breve contextualização de seus trabalhos.

Como já foi apontado, houve uma renovação do interesse na área durante os anos 1980 e 1990, o que podemos compreender como fruto de um grande número de pesquisas que indicavam constantemente que alunos e professores não tinham o que seria uma compreensão adequada do assunto (LEDERMAN; WADE; BELL, 1998). Dentro desse contexto, é possível encontrar uma série de trabalhos avaliando as concepções dos alunos e professores, bem como propondo novos instrumentos de avaliação para tal.

Durante a segunda metade dos anos 1980 e ao longo dos anos 1990, Lederman se dedicou a estudar esses instrumentos de avaliação (LEDERMAN, 1986, 1992; LEDERMAN; O'MALLEY, 1990; LEDERMAN; WADE; BELL, 1998). Esses estudos se mostraram importantes para compreender o que já havia sido feito na área e quais caminhos estariam se abrindo para os anos seguintes. Lederman (1986), por exemplo, 
nos apresenta em uma revisão a mudança de abordagens na coleta dos dados, partindo de um tratamento estritamente quantitativo na avaliação para uma abordagem mais qualitativa, introduzindo entrevistas individuais como instrumento de avaliação e validação das concepções identificadas. Outro ponto importante apresentado é a inclusão de outras variáveis nesses estudos, como o comportamento dos professores e o clima da sala de aula na mudança de concepções dos alunos (LEDERMAN, 1986; LEDERMAN; DRUGER, 1985).

Lederman compartilha da visão de seus pares a respeito da importância da natureza do conhecimento científico no ensino. Todavia, sua atenção inicial parece estar voltada principalmente para os instrumentos de avaliação e a maneira pela qual as concepções dos alunos e professores podem ser avaliadas.

É importante salientarmos também que, ao avaliarmos as concepções dos alunos e professores acerca da natureza da ciência, é necessário que haja uma distinção entre aquilo que se considera adequado e inadequado. Ora, como já nos apontara Matthews (2012), existe uma grande discussão a respeito da demarcação entre ciência e não ciência e esta discussão se estende à natureza do conhecimento científico. Lederman (1986) reconhece a problemática envolvida em assumir o que deveria ser uma visão adequada e acrescenta que é notável a ausência de tal definição nos trabalhos anteriores. Torna-se necessário compreender o que é a natureza da ciência para Lederman.

Segundo Lederman et al. (2002, p. 498, tradução nossa), quando nos referimos à natureza da ciência, estamos mencionando a "epistemologia e sociologia da ciência, a ciência como um meio de saber, ou os valores e crenças inerentes ao conhecimento científico e seu desenvolvimento". De fato, esta definição é ampla e passível de discussão a respeito de quais aspectos do conhecimento científico faz parte ou não desse conjunto. Todavia, mesmo em meio à inexistência de um consenso definitivo entre filósofos da ciência, historiadores, cientistas e educadores, Lederman et al. (2002) sustentam que essas discussões são irrelevantes para os alunos do ensino básico ${ }^{1}$. Eles acrescentam que:

Em certo ponto, no tempo e dentro de um certo grau de generalidade, existe um discernimento comum (mesmo que sem a existência de uma concordância completa) a respeito da natureza da ciência entre filósofos, historiadores e sociólogos da ciência. (LEDERMAN et al., 2002, p. 499, tradução nossa).

Isto é, para fins do ensino de ciências na educação básica, dentro de certo grau de generalidade, é possível encontrar aspectos da natureza da ciência em que haja bastante concordância e seriam adequados e desejáveis de ser desenvolvidos pelos alunos. Essa concepção veio a ser conhecida como 'Visão Consensual'. Além dos integrantes de seu grupo de pesquisa, outros autores como Gil-Pérez et al. (2001), McComas (2008), McComas, Almazroa e Clough (1998), e Osborne et al. (2003) somam as vozes que defendem essa concepção.

Preocupado também com a ferramenta pela qual seriam avaliadas as concepções dos alunos, Lederman e seus colaboradores desenvolvem o VNOS (Views of Nature of Science Questionnaire), para o qual selecionaram oito aspectos da natureza do

'Originalmente indicados como $k$-12 students, seriam os alunos cursando as séries que equivalem ao ensino básico no Brasil (ensino fundamental e médio). 
conhecimento científico que seriam avaliados por meio de seu questionário. São esses aspectos aos quais Matthews (2012) se refere como Os sete de Lederman.

O primeiro aspecto se refere à natureza empírica da ciência ou do conhecimento científico. Como Lederman et al. (2002) pontuam, a Ciência é, pelo menos parcialmente, baseada na observação da natureza e essa observação tem um papel central na validação de alegações dos cientistas. Embora grande parte dos fenômenos não possa ser observada diretamente, é importante que se discuta o papel dos instrumentos, da percepção e do referencial teórico mediadores dessa observação.

O segundo aspecto, que não se encontra na lista apresentada por Matthews (2012), refere-se à observação, inferência e entidades teóricas na Ciência. Lederman et al. (2002) iniciam por afirmar que os estudantes deveriam saber diferenciar observações de inferências, sendo a primeira um conjunto de afirmações descritivas sobre fenômenos naturais que podem ser acessados diretamente e a última, afirmações sobre fenômenos que não podem ser acessados diretamente pelos sentidos. Lederman et al. (2002) afirmam que compreender essa distinção dá início ao entendimento de uma variedade de entidades teóricas e inferenciais e outros termos referentes ao conhecimento científico. Um exemplo dessas entidades seriam os modelos.

O terceiro aspecto trata da distinção entre teorias e leis científicas. Esse aspecto se relaciona intimamente com o anterior e é frequentemente alvo de confusão entre os alunos. Lederman et al. (2002, p. 500, tradução nossa) compreendem teorias científicas como "[...] um sistema de explicações bem estabelecido, altamente substanciado e internamente consistente". Teorias unem observações que antes pareciam não possuir relações, geram problemas de pesquisa e guiam investigações futuras. Por se basearem em afirmações, axiomas e postularem a existência de entidades não observáveis, as teorias não podem ser diretamente testadas. As leis, em contrapartida, tratam das relações entre fenômenos observáveis.

O quarto aspecto diz respeito ao papel da criatividade e da imaginação na natureza do conhecimento científico. Lederman et al. (2002) afirmam que, apesar de se basear nas observações, a Ciência é uma atividade humana, viva e requer a elaboração de explicações e entidades científicas que ultrapassam aquilo que é observado, demandando criatividade por parte dos cientistas.

O quinto aspecto concerne à influência das teorias sobre o conhecimento científico. Para Lederman et al. (2002, p. 501, tradução nossa), "[...] o comprometimento teórico e disciplinar dos cientistas, suas crenças, conhecimentos prévios, treinamento, experiências e expectativas influenciam seu trabalho".

O sexto aspecto se refere à imersão cultural e social em que o conhecimento científico se encontra. "A ciência como um empreendimento humano é praticada em um contexto maior e seus praticantes são o produto dessa cultura" (LEDERMAN et al. 2002, p. 501, tradução nossa). A ciência afeta e é afetada por esses elementos. Entre eles, encontramos a política, os fatores socioeconômicos, a filosofia e a religião, dentre muitos outros.

O sétimo e penúltimo aspecto é bastante discutido como o mito do "Método Científico". Segundo Lederman et al. (2002), este é um dos maiores equívocos sobre o conhecimento científico. "O mito do método científico é frequentemente manifestado na crença de que existe uma série de passos, como uma receita, que todos os cientistas seguem quando fazem ciência" (LEDERMAN et al., 2002, p. 501, tradução nossa). 
Por último, encontramos a natureza provisória do conhecimento científico. "Conhecimento científico, embora confiável e duradouro, nunca é absoluto" (LEDERMAN et al., 2002, p. 502, tradução nossa). O conhecimento científico se modifica à medida que novas evidências, novas teorias e mudanças no contexto sociocultural ocorrem.

Como apontamos na seção anterior, não são poucas as críticas feitas por Matthews a essa visão consensual. Entretanto, as próprias críticas também são passíveis de discussão. Na próxima seção vamos nos dedicar a analisar essas críticas direcionadas ao trabalho de Lederman e discutir a sua pertinência dentro do contexto do trabalho apresentado pelo grupo.

\section{Sobre as críticas}

Em sua proposta, conforme já fora mencionado, Matthews (2012) afirma que uma mudança no foco que vem sendo dado às pesquisas sobre a Natureza da Ciência evitaria algumas "armadilhas" filosóficas e educacionais nas quais um grande número de pesquisas vinha caindo. Assim, como essas armadilhas parecem guiar as críticas que Matthews faz a essas pesquisas, nós as utilizaremos como guias para nossa discussão.

A primeira armadilha consiste na confusão criada ao se juntarem elementos da epistemologia, sociologia, psicologia e filosofia, dentre outras áreas, em uma única lista a respeito da Natureza da Ciência, ou seja, na definição que alguns grupos, mais especificamente, o grupo de Lederman, têm a respeito do que seria a natureza do conhecimento científico. Como já fora citado anteriormente, para Lederman et al. (2002, p. 498, tradução nossa), ao se referir à natureza do conhecimento científico, estamos nos referindo à "[...] epistemologia e sociologia da ciência, a ciência como um meio de saber, ou os valores e crenças inerentes ao conhecimento científico e seu desenvolvimento".

Conforme já comentamos anteriormente, são áreas que têm diferentes limites e ópticas sobre a ciência e, para Matthews, essa mistura 'confusa' seria motivo suficiente para uma mudança de foco mais flexível. Essa afirmação reforça a maneira pela qual Matthews (2012, p. 4, tradução nossa) concebe essa visão consensual que, para ele, é "essencialista e focada na epistemologia". Além disso, Matthews também parece conceber a visão consensual como "uma lista de condições necessárias e suficientes para uma prática ser científica" (2012, p. 4, tradução nossa). Essas afirmações parecem, em um primeiro momento, nos mostrar uma visão um tanto descontextualizada do que seria a visão consensual, personificada neste trabalho em Lederman e seu grupo. Algo que corrobora essa afirmação é o fato de, ao citar um grande número de pesquisas na área, conferindo as citações, vermos apenas citações ao grupo de Lederman.

Lederman, Antik e Bartos (2014, p. 287, tradução nossa) apresentam, já no resumo de seu trabalho, um comentário que servirá para desmistificar essa má interpretação. Eles dizem que "[...] é importante lembrar que os aspectos da natureza do conhecimento científico não devem ser considerados como uma lista compreensiva, mas sim um conjunto de ideias importantes para estudantes adolescentes aprenderem sobre o conhecimento científico". Ou seja, o grupo de Lederman assume uma interpretação flexível a respeito desses aspectos, abrindo espaço para a discussão deles em sala de aula, um objetivo compartilhado pela proposta de Matthews. 
Outros pontos a serem discutidos se referem à compreensão de Matthews com relação à lista de Lederman. O autor vê a seleção desses aspectos como um ato de privilegiar uma posição controversa a respeito da natureza da ciência que ainda seria bastante debatida, além de ver nessa seleção a pressuposição de uma solução particular da disputa pela demarcação entre ciência e não ciência.

Podemos começar com a primeira afirmação. É de conhecimento geral aos que se aventuram em estudar a natureza do conhecimento científico que a área é preenchida por controvérsias. Este fato não escapa ao conhecimento de Lederman e seu grupo. Todavia, eles afirmam que "[...] essa quantidade de discordâncias sobre definições específicas ou significados de NdC que continuam a existir entre filósofos, historiadores, sociólogos e educadores científicos são irrelevantes para os estudantes da escola básica" (LEDERMAN et al., 2002, p. 499, tradução nossa). Eles acrescentam que, em algum momento, no tempo e com certo grau de generalização, existe certo conhecimento comum com relação ao qual esses grupos compartilham uma boa concordância ou, sob a visão de Lederman, concordância suficiente para a educação básica. É nesse sentido de generalização e relevância ao ensino que Lederman e seu grupo seleciona alguns aspectos para a confecção do VNOS, instrumento utilizado para avaliar o conhecimento dos alunos. Em seu artigo de 2014, Lederman e seu grupo afirma que "[...] é abundante a existência de debates a respeito de uma descrição "definitiva" da NdC, mas que são dificilmente produtivas" (LEDERMAN, ANTIK, BARTOS, 2014, p. 286, tradução nossa).

Quanto à questão da demarcação é importante ressaltarmos que, durante a análise dos artigos publicados por Lederman e seu grupo, não encontramos menção ao problema da demarcação e a sua lista de aspectos não é apresentada como uma solução para este problema. Afirmações anteriores já deixam clara a posição do grupo e é reforçada quando seus membros afirmam que "[...] eles não estão advogando uma definição definitiva ou universal desse construto" nem que "sua 'lista' seja a única lista ou definição" (LEDERMAN, ANTIK, BARTOS, 2002, p. 286, tradução nossa).

Finalizando a discussão das armadilhas, percebemos uma compreensão equivocada de Matthews, em relação ao trabalho de Lederman, não apenas na maneira pela qual este compreende a visão consensual, como também na questão da avaliação. Para isso, precisaremos explorar o VNOS, instrumento desenvolvido pelo grupo de Lederman para avaliar as visões dos alunos e professores a respeito da NdC.

Como nos apresentam os autores, Lederman, Wade e Bell (1998), Lederman et al. (2002) e Matthews (2012), a alfabetização científica é um objetivo educacional aceito de forma geral em todo o mundo e fomentar visões adequadas a respeito da natureza do conhecimento científico tem uma relação íntima com esse objetivo. Propostas voltadas para alcançar essa meta abundam, porém, um problema comum encontrado reside nos instrumentos utilizados para a avaliação das concepções de alunos e professores. Lederman, Wade e Bell (1998) nos apresentam uma revisão bastante ampla dessas avaliações e dos métodos empregados por meio desses instrumentos. Como nos apontam, no início dos anos 1960 havia uma ênfase em uma abordagem quantitativa nessas avaliações. O cenário foi se modificando, incluindo a utilização de questões mais abertas e o acompanhamento por meio de entrevistas, como maneira de aumentar o valor e a confiabilidade dos resultados. Outro fator que 
Lederman (1992, p. 332, tradução nossa) aponta como relevante nessas avaliações é a "[...] relação entre as concepções dos professores, sua prática em sala de aula e as concepções dos alunos".

O Views of Nature of Science Questionnaire (VNOS), ou questionário de visões da natureza da ciência, é um instrumento que, combinado com entrevistas, pretende fornecer uma avaliação significativa das concepções dos alunos. Portanto, não se trata de uma medição de conhecimento "[...] julgado e avaliado pela capacidade dos alunos identificarem um determinado número de enunciados declarativos a respeito da natureza da ciência" (MATTHEWS, 2012, p. 4, tradução nossa). Há preocupação também dos autores em explicitar o que chamaram de "avaliação significativa". Segundo eles:

\footnotetext{
'Avaliação significativa' se refere às abordagens de avaliação que servem como um aspecto integral do processo de aprendizado, provendo professores e estudantes com informação e oportunidades para esclarecer significados, encorajar discussões e promover o aprendizado (ZESSOULES; GARDNER, 1991 apud LEDERMAN et al., 2002, p. 498, tradução nossa).
}

Para confeccionar um instrumento de avaliação das concepções, é necessário definir aquilo que se considera 'adequado'. Lederman (1986) já nos apontava a notável ausência dessa definição nos antigos instrumentos de avaliação. Ele nos provê em seu trabalho uma síntese de aspectos da natureza da ciência que estariam presentes em Showalter (1974 apud LEDERMAN, 1986, p. 92) e Rubba (1977 apud LEDERMAN, 1986, p. 92) ${ }^{2}$. São estes os aspectos: Moral, Provisoriedade, Expressão de criatividade dos cientistas, Parcimônia, Testabilidade e União (Coerência Global) (LEDERMAN, 1986). É possível ver a influência desse delineamento do que seria adequado no trabalho de 2002. Como já fora mencionado anteriormente, não há, em momento algum, defesa de que a lista de Lederman seria a única a representar corretamente a natureza do conhecimento científico, tampouco a defesa de que esses aspectos devam ser ensinados como uma lista declaratória a ser decorada.

Outro ponto a ser explorado é a insistência de Matthews (2012) em apontar a necessidade de refinamento filosófico nos aspectos que ele batizou de os sete de Lederman. Esse ponto é central em sua crítica e permeia as armadilhas filosóficas e educacionais já citadas. Analisando esses itens, Matthews aponta uma ambiguidade nos itens advinda dessa falta de refinamento. De fato, quando se discute a respeito da natureza empírica da ciência, por exemplo, é relevante para aqueles que se dedicam aos estudos da Filosofia da Ciência debater a respeito da realidade de entidades explicativas propostas nas teorias científicas; porém, para alunos do ensino básico, basta compreender que a ciência é parcialmente baseada em observações do mundo natural e é necessário compreender a diferença entre observações e inferências. Novamente, voltamos à Lederman et al. (2002, p. 499, tradução nossa) quando os autores sustentam que

As generalizações apresentadas na seguinte discussão dos aspectos da Natureza da Ciência devem ser interpretadas no contexto da educação básica em ciências, não no contexto da educação de alunos a se graduarem em filosofia e história da ciência.

${ }^{2}$ Não foi possível ter acesso online ou físico a estes trabalhos. 
Matthews (2012) parece não compreender ou, no pior dos casos, parece ignorar o contexto no qual esses aspectos foram selecionados. Eles não compõem uma lista declarativa que deveria ser decorada e avaliada em seguida, mas servem como um ponto de partida para a discussão que será adaptada aos níveis das séries correspondentes e fomentarão o aprendizado futuro. É importante apontar também que a proposta de Matthews também poderia cair no mesmo 'pecado' de educadores desavisados compreenderem sua lista como outra mais longa a ser decorada e avaliada.

\section{Considerações finais}

Podemos ver que as críticas feitas por Matthews giram em torno da lista de aspectos de Lederman. Tanto as armadilhas apontadas quanto as críticas mais diretas têm o suposto caráter declarativo e filosoficamente confusos como alvo. Embora apresente argumentos bem desenvolvidos contra essas características, Matthews parece perder um ponto bastante importante nessa discussão e nos faz questionar a validade de suas críticas: Lederman e seu grupo não defendem que esses aspectos sejam ensinados e avaliados da forma apresentada por Matthews. O autor apresenta uma visão bastante descontextualizada dessa chamada visão consensual, tornando suas críticas um tanto quanto enviesadas. Ora, é possível até encontrar momentos em que os autores estão defendendo o mesmo método de ensino da Natureza da Ciência e isso parece passar despercebido por Matthews.

Nosso objetivo não é desqualificar qualquer parte desse debate, mas defender que as críticas, quais forem, sejam feitas dentro do contexto no qual o trabalho é proposto, evitando assim que acabem surgindo disputas desnecessárias.

\section{Referências}

ALLCHIN, D. Evaluating knowledge of the nature of (whole) science. Science Education, Hoboken, v. 95, n. 3, p. 518-542, 2011. DOI: https://doi.org/10.1002/sce.20432.

ALLCHIN, D. Beyond the consensus view: whole science. Canadian Journal of Science, Mathematics and Technology Education, London, v. 17, n. 1, p. 18-26, 2017. DOI: https://doi.org/gtfq.

BELL, R. L.; LEDERMAN, N. G. Understandings of the nature of science and decision making on science and technology based issues. Science \& Education, Hoboken, v. 87, n. 3, p. 352-377, 2003. DOI: https://doi.org/10.1002/sce.10063.

GIL-PÉREZ, D. ; MONTORO, I. F. ; CARRASCOSA ALÍS, J. ; CACHAPUZ, A. ; PRAIA, J. Para uma imagem não deformada do trabalho científico. Ciência \& Educação, Bauru, v. 7, n. 2, p. 125-153, 2001. DOI: https://doi.org/gpq6.

IRZIK, G.; NOLA, R. A family resemblance approach to the nature of science for science education. Science \& Education, Hoboken, v. 20, n. 7-8, p. 591-607, 2011. DOI: https://doi.org/fhdvjp.

LEDERMAN, N. G. Students' and teachers' conceptions of the nature of science: a review of the research. Journal of Research in Science Teaching, Hoboken, v. 29, n. 4, p. 331-359, 1992. DOI: https://doi.org/10.1002/tea.3660290404.

LEDERMAN, N. G. Students' and teachers' understanding of the nature of science: a reassessment. School Science and Mathematics, USA, v. 86, n. 2, p. 91-99, 1986. DOI: https://doi.org/b7xvgn.

LEDERMAN, N. G.; DRUGER, M. Classroom factors related to changes in students' conceptions of the nature of science. Journal of Research in Science Teaching, Hoboken, v. 22, n. 7, p. 649-662, 1985. DOI: https://doi.org/fjf9zz. 
LEDERMAN, N. G.; O'MALLEY, M. Student's perceptions of tentativeness in science: development, use and sources of change. Science \& Education, Hoboken, v. 74, n. 2, p. 225-239, 1990. DOI: https://doi.org/fjdzjt.

LEDERMAN, N. G.; ANTIK, A.; BARTOS, S. Nature of science, scientific inquiry, and socio-scientific issues arising from genetics: a pathway to developing a scientifically literate cintizenry. Science \& Education, Hoboken, v. 23, n. 2, p. 285-302, 2014. DOI: https://doi.org/f5spf5.

LEDERMAN, N. G.; WADE, P. D.; BELL, R. L. Assessing the nature of science: what is the nature of our assessments? Science \& Education, Hoboken, v. 7, n. 6, p. 595-615, 1998. https://doi.org/ d4g57r.

LEDERMAN, N. G.; ABD-EL-KHALICK, F.; BELL, R. L.; SCHWARTZ, R. S. Views of nature of science questionnaire: toward valid and meaningful assessment of learner's conceptions of nature of science. Journal of Research in Science Teaching, Hoboken, v. 39, n. 6, p. 497-521, 2002. DOI: https://doi.org/10.1002/tea.10034.

MARTINS, A. F. P. Natureza da ciência no ensino de ciências: uma proposta baseada em 'temas' e 'questões'. Caderno Brasileiro de Ensino de Física, Florianópolis, v. 32, n. 3, p. 703-737, 2015. DOI: https://doi.org/gzbc.

McCOMAS, W. F. Seeking historical examples to illustrate key aspects of the nature of science. Science \& Education, Hoboken, v. 17, n. 2-3, p. 249-263, 2008. DOI: https://doi.org/cp698z.

McCOMAS, W. F.; ALMAZROA, H.; CLOUGH, M. The nature of science in science education: an introduction. Science \& Education, Hoboken, v. 7, n. 6, p. 11-532, 1998. DOI: https://doi.org/cxkz9f.

MATTHEWS, M. R. Changing the focus: from nature of science to features of science. In: KHINE, M. S. (ed.). Advances in Nature of Science Research. Dordrecht: Springer, 2012. p. 3-26.

OSBORNE, J. F.; COLLINS, S.; RATCLIFFE, M.; MILLAR, R.; DUSCHL, R. What 'ideas-about-science' should be taught in school science?: a Delphi study of the expert community. Journal of Research in Science Teaching, Hoboken, v. 40, n. 7, p. 692-720, 2003. DOI: https://doi.org/10.1002/ tea.10105.

PRAIA, J. F.; GIL-PÉREZ, D.; VILCHES, A. O papel da natureza da ciência na educação para a cidadania. Ciência \& Educação, Bauru, v. 13, n. 2, p. 141-156, 2007. DOI: https://doi.org/d76g57.

PUMFREY, S. History of science in the national science curriculum: a critical review of resources and their aims. The British Journal for History of Science, London, v. 24, n. 1, p. 61-78, 1991. DOI: https://doi.org/dkwhz3. 